\title{
Preformulation Study of 50\% Ethanol Extract of Mangosteen Rind (Garcinia mangostana L.)
}

\author{
Sabrina Dahlizar ${ }^{*}$, Yuni Anggraeni ${ }^{2}$, Hanny Narulita ${ }^{3}$ \\ \{sabrina@uinjkt.ac.id ${ }^{1}$,yuni.anggraeni@uinjkt.ac.id²,hanny_narulita@yahoo.com ${ }^{3}$ \} \\ *corresponding author \\ Pharmacy Study Program, Faculty of Health Sciences \\ UIN Syarif Hidayatullah Jakarta, Ciputat, 15419. Indonesia ${ }^{1,2,3}$
}

\begin{abstract}
Garcinia mangostana rind containing alpha-mangostin has the potential to be used as an antioxidant. This study aimed to determine the physicochemical properties and stability of alpha-mangosteen in the $50 \%$ ethanol extract of mangosteen rind as a parameter in the pre-formulation study. Physicochemical properties were evaluated for specific and nonspecific extract parameters, determining the optimum wavelength and solubility test. The stability test was carried out at a temperature of $45 \pm 5^{\circ} \mathrm{C}$ with relative humidity $75 \pm 5 \%$ for 21 days, in acidic and alkaline conditions. The alpha-mangostin content was analyzed using a UV-Vis spectrophotometer. The results showed that the extract was purplish brown, has an aromatic smell, and a bitter taste. The dissolved compound in water and ethanol were $62.54 \pm 1.09 \%$ and $87.05 \pm 0,43 \%$, respectively, the specific density of $5 \%$ extract was 1.036 , loss on drying $6.66 \pm 0,11 \%$, ash content $5.07 \pm 0.23 \%$, ash content insoluble in acidic was $0.13 \pm 0.02 \%$, alpha-mangosteen content in the extract was $3.85 \pm 0.03 \%$. The solubility test showed that alpha-mangosteen in the extract has a solubility value of 1: 16064 in water. The stability test showed that the levels of alphamangostin decreased significantly $(\mathrm{p} \leq 0.05)$ at $45 \pm 5^{\circ} \mathrm{C}$ and relative humidity $75 \pm 5 \%$ for 21 days. Mangosteen rind extract was unstable in the extremely acidic and alkaline conditions.
\end{abstract}

Keywords: Alpha mangostin, garcinia mangostana L., specific parameter, solubility, stability

\section{Introduction}

Garcinia mangostana L., generally known as mangosteen, is a fruit that is a part of the Clusiaceae family. The largest component of mangosteen is its skin, which composes up to 70 $75 \%$ of the fruit's total mass. According to previous studies, it has been found that mangosteen skin contains pharmacological compounds and antioxidants, namely flavonoid, tannin, and xanthone [1]. One of the derivatives of xanthone is alpha-mangostin. Alpha-mangostin is a major compound derived from xanthone which serves as an antioxidant, antitumor, antiinflammatory, antiallergic, and antibacterial. The property that receives the most attention is its ability to serve as an antioxidant [2].

Weecharangsan et al. (2006) conducted research on antioxidant properties in mangosteen skin extract with water extract, $50 \%$ ethanol, and $95 \%$ ethyl acetate. The results showed that all extracts had the potential to deflect free radicals. Water extract and $50 \%$ ethanol had the greatest potential in doing so. This was because xanthone compounds and its derivatives 
provided the antioxidant qualities in the form of phenolic compounds that have polar or semipolar qualities, dissolving back in water and ethanol [3].

Based on the results of this research, mangosteen skin extract has great potential to be used as an antioxidant source. Before it is turned into a dosage form, a pre-formulation study is done to gather information about the characteristics of the substances that will be used [4]. The pre-formulation study is an investigation of physical and chemical characteristics, whether they are individually active or with excipients. A pre-formulation study is the first step in developing the form of the dosage form. The overall purpose of the pre-formulation study is to produce useful information in developing stable drugs. The analysis of physicochemical properties of the extract is done to find out what parameters should be used as benchmarks in creating the formula for the antioxidant source.

Other pre-formulation studies are conducted to investigate stability in other materials used. WHO defines drug stability as the ability for pharmaceutical products to retain physical, chemical, biological, and biopharmaceutical properties within certain boundaries that are determined by its use. Several studies have conveyed the stability of certain drugs, but the stability of certain extracts differ from the results of drug stability tests. Measuring chemical stability in extracts is especially interesting because complex chemical properties are composed of hundreds of different compounds. Testing drug stability in plant extracts plays an important role in developing new drugs. Various environmental conditions, such as light, heat, and humidity, can significantly influence the chemical stability of drugs and dosage forms during storage and use [5].

The scope of this study includes the characterization of the extract (specific and nonspecific parameters), the solubility of alpha-mangostin in water, drug stability at a temperature of $45 \pm 5^{\circ} \mathrm{C}$ with a humidity of $75 \pm 5 \%$, and the effects of $\mathrm{pH}$ on acid and alkaline degradation of mangosteen rind in $50 \%$ ethanol extract (Garcinia mangostana L.).

\section{Method}

\section{Materials}

Mangosteen (Garcinia mangostana, L.) was collected from Padang, West Sumatera, Indonesia. Chloroform, $\mathrm{NaOH}, \mathrm{HCL}$, methanol, iron (III) chloride, $\mathrm{NaCl}$ and ethanol were purchased from Merck, Germany. Alpha mangostin was purchased from Biopurify, China.

\section{Extraction of Mangosteen rind (Garcinia mangostana L.)}

The mangosteen rind powder was macerated using $50 \%$ ethanol, then the macerate was evaporated using a vacuum rotary evaporator at a temperature $45-50^{\circ} \mathrm{C}$, and drying using a vacuum oven at $45^{\circ} \mathrm{C}$ for $24 \mathrm{~h}$.

\section{KLT}

The stationary phase is a silica gel (Si60F254) and the mobile phase were chloroform:ethyl acetate:methanol (8:1:0.5).

\section{Determination of a specific and nonspecific extract parameters}

Specific and nonspecific extract parameters was carried out according to the reference [6]. The specific extract parameters were included identity, organoleptic and compound content in a specific solvent. While the nonspecific extract parameters were total ash content, acid insoluble ash content, density and loss on drying. 


\section{Determination of maximum wavelength of extract}

$25 \mathrm{mg}$ of extract was dissolved in $50 \mathrm{~mL}$ methanol, and diluted to $25 \mathrm{ppm}$. Maximum wavelength was obtained from the wavelength whose the absorbance gives the maximum peak.

\section{Determination of maximum wavelength of alpha-mangostin}

$5.0 \mathrm{mg}$ alpha-mangostin in $25 \mathrm{~mL}$ methanol (200 ppm), diluted to $8 \mathrm{ppm}$, then maximum wavelength was obtained from the wavelength whose the absorbance gives the maximum peak.

\section{Determination of alpha-mangostin content in the Mangosteen rind extract (Garcinia mangostana L.)}

Calibration curve was made by dissolved $5.0 \mathrm{mg}$ of alpha-mangostin standard in methanol $25 \mathrm{~mL}$ then diluted to $0.5 ; 2,4,8,10,12,14$, and $16 \mathrm{ppm}$. Alpha-mangostin in the extract was determined by using spectrofotometry UV-VIS. $25 \mathrm{ppm}$ extract solution was used as a sample. Alpha-mangosteen level obtained by compared absorbance of the extract with the absorbance of alpha mangosteen standard in the obtained calibration curve.

\section{Solubility test}

Solubility test was carried out according to Higuchi and Connors method [7]. $100 \mathrm{mg}$ of extract was dissolved in $25 \mathrm{~mL}$ aquabidest, it was shake for $72 \mathrm{~h}$ at $37{ }^{\circ} \mathrm{C}$ [7]. The obtained solution was filtered by - filter membrane $0.20 \mu \mathrm{m}$ then it was diluted 100 times to $40 \mathrm{ppm}$, the absorbance was measured by using spectrophotometer UV-Vis at the maximum wavelength. The solubility test was carried out triplo.

\section{Stability test of alpha-mangostin in the Mangosteen rind extract (Garcinia mangostana L.)}

Stability test in specific temperature and humidity [5] was carried out at a temperature $45 \pm 5{ }^{\circ} \mathrm{C}$ and relative humidity $75 \pm 5 \%$ for 21 days. The samples were analyzed at $(\mathrm{t} 0), 2,7,14$, and 21 days after exposed.

Stability test in extremely alkaline conditions (different $\mathrm{pH}$ ) [8] was conducted by dissolving $50 \mathrm{mg}$ of extract in $25 \mathrm{~mL}$ of methanol, then 1 drop of $5 \mathrm{M} \mathrm{NaOH}$ was added before add methanol until $50 \mathrm{~mL}$. The solution was boiled in waterbath for $1 \mathrm{~h}$, then diluted to $25 \mathrm{ppm}$. The absorbance was measured by using spectrophotometer UV-Vis. Stability test in extremely acidic conditions was conducted by using $5 \mathrm{M} \mathrm{HCl}$ with the same method.

\section{Result}

The extraction showed a percent yield of $12.5 \%$. The results from the thin layer chromatography (TLC) of standard alpha-mangostin showed that extracts that were dried in a vacuum oven and without a vacuum oven showed the same pattern (Fig. 1).

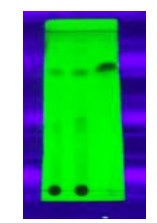

Fig. 1. The results from TLC of (1) Extract were dried in a vacuum (2) Extract were dried without vacuum and (3) standard alpha-mangostin, respectively left to right. 
Specific parameters that were tested included identity, organoleptics, and solubility levels of compounds in ethanol and water. Extract identification aims to provide objectivity from the name and to specify the plant, while the organoleptic observation of the extract aimed to include senses in describing the form, color, fragrance, and taste [6]. Color-wise, mangosteen rind in 50\% ethanol extract was a purplish-brown color. The form of mangostin rind in 50\% ethanol extract was thick and sticky. The thickness of the extract was inversely proportional compared to the extract's contained solvent. The thicker the extract, therefore the lesser the contained extract. Mangosteen skin in 50\% ethanol extract tasted bitter and had a distinct fragrance. The results from the test for the levels of compounds dissolved in ethanol were $87,05 \pm 0,43 \%$ and the levels of compounds dissolved in water were $62 ., 54 \pm 1,09 \%$.

Nonspecific parameters tested specific density, loss on drying, ash content, ash content insoluble in acidic.

Table 1. Characterization extract

\begin{tabular}{cc}
\hline Characterization & Results \\
\hline $\begin{array}{c}\text { Specific Paramater } \\
\text { a. Organoleptic }\end{array}$ & $\begin{array}{c}\text { Purplish } \\
\text { brown, has an aromatic } \\
\text { smell, and a bitter taste. } \\
87.05 \pm 0.43 \%\end{array}$ \\
b. The dissolved & $62.54 \pm 1.09 \%$ \\
compound in ethanol & \\
c. The dissolved compound & \\
in water & 1.036 \\
Nonspecific parameter & $6.66 \pm 0.11 \%$ \\
a. Density & $5.07 \pm 0.23 \%$ \\
b. Loss on drying (b/b) & $0.13 \pm 0.02 \%$ \\
c. ash content (b/b) & \\
d. ash content insoluble in & \\
acidic $\quad$ &
\end{tabular}

Specific density was measured at 1.,036 for extract concentration 5\%, and the percentage of loss on drying from the ethanol extract of mangosteen rind was $6 ., 66 \pm 0,11 \%$. The total ash contained in the extract did not exceed 16.,6. The ash content insoluble in acidic was $0 ., 13 \pm 0.02 \%$. The requirements of ash content insoluble in acidic may not exceed $0.7 \%$.

Determination of maximum wavelength of extract were showed in Fig. 2

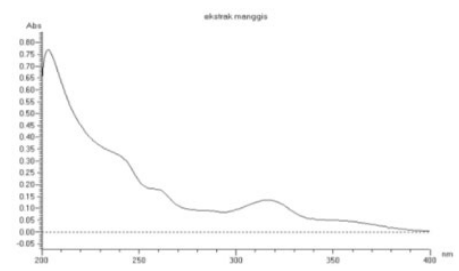

Fig. 2. $\lambda$ Maximum extract

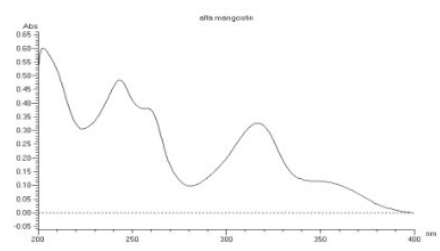

Fig. 3. $\lambda$ Alpha-mangosteen

The length of $\lambda$ maximum extract showed there was a maximum absorbance at wavelengths of $204 \mathrm{~nm}$ and $316 \mathrm{~nm}$. The wavelength of alpha-mangostin is $316 \mathrm{~nm}$. In this 
study, the levels of alpha-mangostin were determined by standard alpha-mangostin. The maximum wavelengths of alpha-mangostin found were $204 \mathrm{~nm}, 243 \mathrm{~nm}$, and $316 \mathrm{~nm}$. The measurement of alpha-mangostin was done at a wavelength of $316 \mathrm{~nm}$. The aim of measuring the wavelengths is to distinguish between other compounds that also have xanthone rings.

The results of the calibrated curve showed the regression equation $y=-0 ., 00257+0 ., 057 x$ with the R value of 0.999 (Fig. 4). The amount of alpha-mangostin contained in mangosteen rind in $50 \%$ ethanol extract was $3 ., 85 \pm 0 ., 03 \%$.

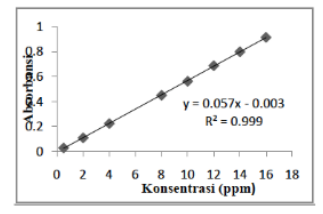

Fig. 4. Calibration curve of alpha-mangostin

The solubility test was conducted to determine the levels of absorption of the alphamangostin structure contained in the extract in a water solvent. The method used for the solubility test was the Higuchi and Connors method, where the extract with added water is shaken for 72 hours at a temperature of $37^{\circ} \mathrm{C}$ [9]. The solubility rate of alpha-mangostin in water was $1: 16064$. This number is within the range of $>10.000$, meaning that alpha-mangostin is practically insoluble in water.

Table 2. Stability test at temperature $45 \pm 5^{\circ} \mathrm{C}(\mathrm{RH} 75 \pm 5 \%)$

\begin{tabular}{llll}
\hline $\begin{array}{l}\mathrm{Da} \\
\mathrm{y}\end{array}$ & $\begin{array}{l}\text { Conc. (mg } \pm \\
\text { SD) }\end{array}$ & $\begin{array}{l}\text { Conc. } \\
(\%)\end{array}$ & $\begin{array}{l}\text { Alpha- } \\
\text { mangosteen } \\
(\%)\end{array}$ \\
\hline 0 & $2.221 \pm 0,198$ & $4.44 \%$ & $100 \%$ \\
2 & $2.080 \pm 0,030$ & $4.16 \%$ & $93.65 \%$ \\
7 & $1.870 \pm 0,182$ & $3.74 \%$ & $84.19 \%$ \\
14 & $1.683 \pm 0,103$ & $3.37 \%$ & $75.78 \%$ \\
21 & $1.530 \pm 0,073$ & $3.06 \%$ & $68.89 \%$ \\
\hline
\end{tabular}

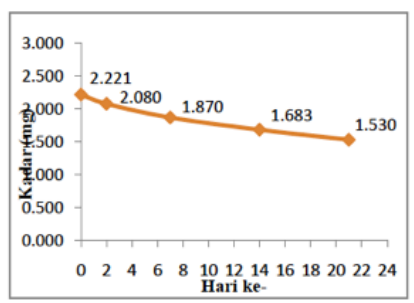

Fig. 5. The decrease of alpha-mangosteen levels in 21 days

The graph (Fig. 5) shows the decrease of alpha-mangostin levels in mangosteen skin in $50 \%$ ethanol extract for a testing period of 21 days. There was an overall $31.11 \%$ decrease from day 0 until day 21 . The results of the Kruskal-Wallis test showed that the stability test had a significant effect as time went by $(p \leq 0,05)$. The results showed that at a temperature of $45 \pm 5^{\circ} \mathrm{C}$ 
and humidity of $75 \pm 5 \%$, the levels of alpha-mangostin decreased over the study period and were statistically significant $(p \leq 0,05)$. Degradation rate of alpha-mangostin in mangosteen skin in $50 \%$ ethanol extract at a temperature of $45 \pm 5^{\circ} \mathrm{C}$ and humidity of $75 \pm 5 \%$ is a second-order reaction with a reaction rate constant of 4,7365x10-4.

Results of Stability Tests in Acid and Base

Stability tests of alpha-mangostin contained in mangosteen skin extract in 50\% ethanol extract was done by dissolving mangosteen skin extract in 50\% ethanol extract in methanol, and then adding $5 \mathrm{M}$ of chloric acid (acid test) and $5 \mathrm{M}$ of sodium hydroxide (alkaline test). Both were heated in a boiling water bath. The basin used must be able to prevent solvent evaporation to maintain the concentration of other extracts inside. After heating, the solution is diluted with methanol up to $25 \mathrm{ppm}$.

The result of alpha-mangostin absorbance in extract during stability tests in acid and base, when compared to the constant, showed an increase in level (Table 3). This raises a question of whether it is the alpha-mangostin levels that are increasing, or if it is a degradation of alpha-mangostin, causing a higher absorption.

Table 3. Absorption levels of alpha-mangostin in extract and standard alpha-mangostin in stability tests in acid and base

\begin{tabular}{llll}
\hline & Blank & Stability in acidic & Stability in base \\
\hline Absorbance alpha-mangosteen in extract & 0,058 & 0,079 & 0,079 \\
& 0,052 & 0,078 & 0,078 \\
& 0,056 & 0,081 & 0,080 \\
& & & \\
Absorbance standard alpha-mangosteen & 0,058 & 0,037 & 0,025 \\
& 0,056 & 0,036 & 0,027 \\
& 0,054 & 0,038 & 0,028 \\
\hline
\end{tabular}

It was found that in the tests done using the TLC plate, there were no spots that showed alpha-mangostin in the extracts that have been treated with acid or base (Fig. 6). The TLC illustrated that the alpha-mangostin in the extract was degraded to the point that no spots were sighted, unlike what happened with the standard alpha-mangosteen. Other than tests of alphamangostin contained in the extract, tests were also done using standard alpha-mangostin to give comparison. When compared to the constant, a decrease of the absorbance level in standard alpha-mangostin was observed. These results show that there was a degradation of standard alpha-mangostin.

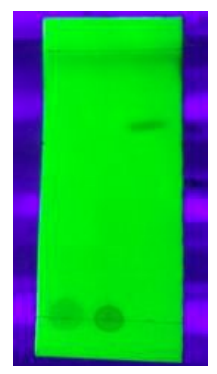

Fig. 6. TLC results in acid, base, and standard alpha-mangostin, respectively from left to right. 


\section{Discussion}

The objective of the solubility test was to ease the formulation of mangosteen rind ethanol extract, where the solubility of a compound heavily influences the dosage form to ensure an effective therapeutic effect. To ensure that a drug can enter the circulation systemic and produce a therapeutic effect, the drug needs to be dissolved beforehand. Therefore, the beforehand knowledge of solubility of drug material is important to know [10].

In a study conducted by Lim et al. (2011), it was found that there was a decrease in xanthone levels (alpha-mangostin and 8-desoxygartanin) after drying. This is caused by enzymatic degradation or thermal degradation. Degradation enzymes work below a temperature of $50^{\circ} \mathrm{C}$. After the extract enters a temperature of $50^{\circ} \mathrm{C}$ after 45 minutes, enzymes that play a role in degrading alpha-mangostin levels in the extract start to become inhibited. A high temperature helps in activating degrative enzymes, for example, polyphenol oxidase (PPO). However, some polyphenols will still be able to degrade because of enzyme activities before activation $[11,12]$.

It can be concluded that the loss of alpha-mangostin observed in stability test is caused by factors other than temperature and the existence of degrading enzymes inside the compound itself, which is catalyzed by temperature.

During the addition of acid and alkaline, the ethanol extract of mangosteen rind showed a change in color. After adding chloride acid $(5 \mathrm{M})$, the extract solution that was originally golden yellow turned into a reddish color after being heated. After adding the base sodium hydroxide, the color of the solution changed into a dark brown color. This change of color in the extract solution showed that a reaction took place, as explained by a study conducted by Huang et al. (2012). It was explained that, the absorbance from a polyphenol substance produced two points of absorption between 200 and $360 \mathrm{~nm}$. After being treated with a base, none of the absorptions that were earlier observed were detected in the wavelength. On the spectrum, the value of absorbance increased significantly between the wavelengths $300-400 \mathrm{~nm}$. The results showed absorbance were equal to the UV-Vis absorbance spectrum in benzoquinone [13].

Another study found that polyphenol is a solution that can easily oxidate into quinone, and $\mathrm{pH}$ is an important factor that influences the rate of said oxidation. From the results of the study, it can be assumed that quinone formed in solutions of mangosteen extract at an extreme $\mathrm{pH}$ can cause the extract to become unstable [13].

After comparing the absorbance results between mangosteen skin in $50 \%$ ethanol extract and standard alpha-mangostin treated with acid and base, it can be concluded that the cause of increased absorption in the extract is not only because of alpha-mangostin, but also other components from the polyphenol group that is easily oxidized into quinone, causing the increase of absorption. This is proven by the decrease of absorbance in alpha-mangostin.

\section{Conclusion}

The results of the specific parameter of mangosteen rind in 50\% ethanol extract identified the extract through the observation of a brown-purplish color in organoleptic extract, an aromatic fragrance, bitter taste, and a proportion of extract compounds dissolved in water of $62.54 \pm 1,09 \%$ and the proportion of extract compounds dissolved in ethanol of $87.053 \pm 0.43 \%$. The results of this nonspecific parameter test have fulfilled the requirements. 
The solubility of alpha-mangostin in mangosteen extract in $50 \%$ ethanol extract in distilled water was 1:16064. This ratio shows that practical alpha-mangostin is not soluble in water. In the stability test with a temperature of $45 \pm 5^{\circ} \mathrm{C}$ and humidity of $75 \pm 5 \%$, it was found that the levels of alpha-mangostin contained in the extract decreased by $31 ., 11 \%$ over a period of 21 days and is statistically significant. The results of the acid and base stability test showed that mangosteen rind in 50\% ethanol extract was unstable in extremely acid or alkaline solutionenvironments.

Acknowledgments. The authors wish to thank to department of pharmacy, faculty of health sciences UIN Syarif Hidayatullah Jakarta.

\section{References}

[1] Dungir, Stevi G., Dewa G. Katja, Vanda S. Kamu. Aktivitas antioksidan ekstrak fenolik dari kulit buah manggis (Garcinia mangostana L.). Jurnal MIPA UNSRAT Online (1): 11-1. (2012)

[2] Jung HA, Su BN, Keller WJ, Mehta RG, Kinghorn AD. 2006. Antioxidant xanthones from the pericarp of Garcinia mangostana (Mangosteen). J Agric Food Chem., 54(6):2077-2082 . (2006)

[3] Weecharangsan,W., Opanasopit, P., Sukma, M., Ngawhirunpat, T., Sotanaphun, U., Siripong, P. Antioxidative and neuroprotective activities of extract from the fruit hull of mangosteen (Garcinia mangostana Linn.). Med Princ Pract 15,281-287. (2006)

[4] Singh, Anoop Kumar., R. Panner Selvam, T. Sivakumar. Isolation, characterisation and formulation properties of a new plant gum obtained from mangifera indica. Int $J$ Pharm Biomed Res, 1(2), 35-41. (2010)

[5] Lopes, Gisely C., Renata Longhini, Paulo Victor P. dos Santos, Adriano A. S. Ara'ujo, Marcos Luciano Bruschi, and Jo ao Carlos P. deMello. 2012. Preliminary assessment of the chemical stability of dried extracts from Guazuma ulmifolia Lam. (Sterculiaceae). International Journal of Analytical Chemistry Volume, Article ID 508945. doi:10.1155/2012/508945. (2012)

[6] Depkes Republik Indonesia. 2000. Parameter Standar Umum Ekstrak Tumbuhan Obat. Jakarta: Departemen Kesehatan Republik Indonesia, Dirjen POM. (2000)

[7] Higuchi and connor

[8] Walash, Mohamed I., Fathallah F Belal, Nahed M El-Enany and Heba Elmansi. 2011. Development and validation of stability indicating method for determination of sertraline following ICH guidlines and its determination in pharmaceuticals and biological fluids. (2011)

[9] Doile, Mayara M., Keila A. Fortunato, Iara C. Schmucker, Sacha K. Schucko, Marcos A.S. Silva, and Patrick O. Rodrigues. 2008. Physicochemical properties and dissolution studies of dexamethasone acetate- $\beta$-cyclodextrin inclusion complexes produces by different methods. AAPS PharmSciTech, Vol. 9, No. 1. DOI: 10.1208/s12249-008-9042-z. (2008)

[10] sofyan, henni, amri

[11] Med. Princ. Prac.t 15,281-287. Young-Won Chin dan A. Douglas Kinghorn. Structural Characterization, Biological Effects, and Synthetic Studies on Xanthones from Mangosteen (Garcinia mangostana), a Popular Botanical Dietary Supplement. The Ohio State University. November 1; 5(4): 355-364.DOI:10.2174/157019308786242223. (2008)

[12] Savarnakuta, Peamsuk, Chanchawee Chaweerungrat, Sakamon Devahastin. 2011. Effects of drying methods on assay and antioxidant activity of xanthones in mangosteen rind. Food Chemistry 125:240-247(2011)

[13] Huang, Xuelian, Lei Cheng, R.A.M. Exterkate, Mingdong Liu, Xuedong Zhou, Jiyao Li, J.M. ten Cate. 2012. Effect of $\mathrm{pH}$ on Galla chinensis extract's stability and anti-caries properties in vitro. Achive of Oral Biology 57 (2012):1093-1099. (2012) 